\title{
Asylum Seekers: Our Patients at the Border
}

\author{
Samuel G. Ruchman, $A B$
}

Icahn School of Medicine at Mount Sinai, New York, NY, USA.

J Gen Intern Med 34(12):2908-9

DOI: $10.1007 / \mathrm{s} 11606-019-05218-w$

(C) Society of General Internal Medicine 2019

A sylum is a life-saving intervention for people fleeing violence, torture, and other human rights abuses. Deporting an asylum seeker to his or her country of origin can mean further persecution and even death. ${ }^{1}$ This spring, when President Donald Trump asked officials to further restrict asylum applications by charging application fees and limiting interim work permits, he escalated the administration's war on some of our profession's most vulnerable patients. ${ }^{2}$ He proposed that asylum seekers literally pay the price of freedom, as if they have not already paid in blood and anguish. The White House wants the public to believe that asylum seekers are exploiting immigration policy, rather than that they are innocent families and individuals searching for protection under a widely accepted tenet of international law. So, who are asylum seekers and why are they desperate to enter the United States?

As a medical student, one of my most formative and humbling experiences has been meeting the individuals seeking shelter in the United States and bearing witness to the evidence of their trauma. The Mount Sinai Human Rights Program is one of roughly twenty clinics based at US academic medical centers that provides pro bono forensic evaluations of asylum seekers and documents evidence of their reported abuses in medical-legal affidavits that accompany them to their immigration proceedings. Volunteer physicians, psychologists, and other qualified healthcare professionals in this program have conducted hundreds of evaluations of some of the most marginalized, yet resilient, members of our community.

Our faculty and students have collaborated to document the narratives, physical injuries, and psychological symptoms of women from El Salvador, Guatemala, and Honduras who survived brutal, recurrent sexual and physical assaults by gang members or intimate partners, and then were denied protection by corrupt or powerless police forces in their countries.

The program has photographed scars from machete attacks, contractures from forced burns, and reviewed radiographs of broken bones, offering physical evidence consistent with the reports of people, from the Caribbean to Asia, who fled

Received June 30, 2019

Accepted July 12, 2019

Published online July 25, 2019 political intimidation, persecution, and torture, both by sitting governments and their opposition parties.

Colleagues from the fields of psychiatry and psychology have documented hundreds of cases from around the world of post-traumatic stress, major depression, and other mental sequelae of horrific violence committed because of race, ethnicity, nationality, gender, sexual orientation, political or religious beliefs, and other attributes. ${ }^{3}$

Our gynecologists have dedicated countless hours to women, especially from West Africa, who have survived female genital mutilation/cutting and who hope to protect their daughters from the same permanent trauma. ${ }^{4}$

These are the individuals the US government cannot find the moral authority to welcome. While the courts will not ultimately deem every asylum claim legitimate, our program's experience in documenting physical and psychological evidence of human rights abuses suggests that far too many are grounded in horrific truth.

The legal backlog is indeed a challenge to the asylum system. An estimated 800,000 cases await adjudication, with a years-long wait. ${ }^{5} \mathrm{~A}$ comprehensive and nuanced review of all asylum issues and broader immigration policies is beyond the scope of this essay. In short, solutions to backlog could lie in expanding the immigration court system, better equipping it with judges and other personnel to handle large volumes. Long-term foreign policies to address root causes of violence in our hemisphere, especially in Central America, can mutually benefit both the United States and our neighbors. Instead, the Trump Administration's proposal of raising a financial barrier to realizing asylum rights is as cruel as it disingenuous to the American commitment to freedom.

Healthcare professionals see far too many patients daily made susceptible to illness by poverty, systemic injustice, or substance abuse epidemics. Among this diverse group, some of our most vulnerable patients are at the border or hidden in plain view in our emergency departments, unrecognized, awaiting our expertise and organized action. In one study of a New York City emergency department, more than threequarters of self-reported survivors of torture had never been asked by a physician about this crucial aspect of their history. ${ }^{6}$ Seeking out foundational training in trauma-informed care- that is, best practices in interacting with survivors of diverse traumas - and learning to document human rights abuses as described in the United Nations' Istanbul Protocol is a first step you can take towards both aiding asylum seekers and augmenting our standard clinical acumen. 
With the ability to identify and document medical evidence of human rights abuses, our interventions can truly save lives. One study showed that nearly 90 percent of asylum seekers who received forensic medical evaluation were granted asylum, compared with fewer than 40 percent among those whose evidence was not documented by a medical expert. ${ }^{7}$ Since grant rates vary widely by region and judicial culture, volunteering as a forensic evaluator can be particularly impactful in geographies with few existing resources for asylum seekers.

Documenting the evidence of asylum seekers' experiences reveals stories of both great suffering and unimaginable courage. When we speak about these brave individuals, we must ask ourselves: What would we not do to ensure our families lived without fear of sexual assault, torture, persecution, or murder?

Acknowledgments: The author wishes to express his sincere gratitude to Dr. Kim Baranowski, Dr. Elizabeth Singer, and Dr. Craig Katz for their guidance in finalizing this piece.

Corresponding Author: Samuel G. Ruchman, AB; Icahn School of Medicine at Mount Sinai, 1 Gustave L. Levy Place, New York, NY 10029, USA (e-mail: gus.ruchman@icahn.mssm.edu).

\section{Compliance with Ethical Standards:}

Conflict of Interest: The author declares that he does not have a conflict of interest.
Disclaimer: The views expressed in this piece are those of the author alone and do not necessarily reflect those of the Mount Sinai Human Rights Program or the Icahn School of Medicine at Mount Sinai.

\section{REFERENCES}

1. Stillman S. When Deportation is a Death Sentence. The New Yorker. January 8, 2018. Available at: https://www.newyorker.com/magazine/ 2018/01/15/when-deportation-is-a-death-sentence. Accessed April 30, 2019.

2. Kanno-Youngs Z, Dickerson C. Asylum Seekers Face New Restraints Under Latest Trump Orders. The New York Times. April 29, 2019. Available at: https://www.nytimes.com/2019/04/29/us/politics/trump-asylum. html. Accessed April 30, 2019.

3. Katz CL. Showing 'Credible Fear' Is A Hurdle In Avoiding Deportation. Huffington Post. October 9, 2017. Available at: https://www.huffpost. com/entry/showing-credible-fear-is-a-hurdle-in-avoiding-deportation_b_ 59db7cfee4b0705dc79aa9b0. Accessed April 30, 2019.

4. Lever H, Ottenheimer D, Teysir J, Singer E, Atkinson HG. Depression, Anxiety, Post-traumatic Stress Disorder and a History of Pervasive GenderBased Violence Among Women Asylum Seekers Who Have Undergone Female Genital Mutilation/Cutting: A Retrospective Case Review. J Immigr Minor Health. 2019;21(3):483-489.

5. Lu D, Watkins D. Court Backlog May Prove Bigger Barrier for Migrants Than Any Wall. The New York Times. January 24, 2019. Available at: https://www.nytimes.com/interactive/2019/01/24/us/migrants-borderimmigration-court.html. Accessed April 30, 2019.

6. Hexom B, Fernando D, Manini AF, Beattie LK. Survivors of torture prevalence in an urban emergency department. Acad Emerg Med. 2012;19(10):1158-1165.

7. Lustig SL, Kureshi S, Delucchi KL, Iacopino V, Morse SC. Asylum grant rates following medical evaluations of maltreatment among political asylum applicants in the United States. J Immigr Minor Health. 2008; 10(1):7-15.

Publisher's Note Springer Nature remains neutral with regard to jurisdictional claims in published maps and institutional affiliations. 